\title{
دور التصميم ثلاثي الأبعاد في استحداث أعمال فنيه هعاصره "
}

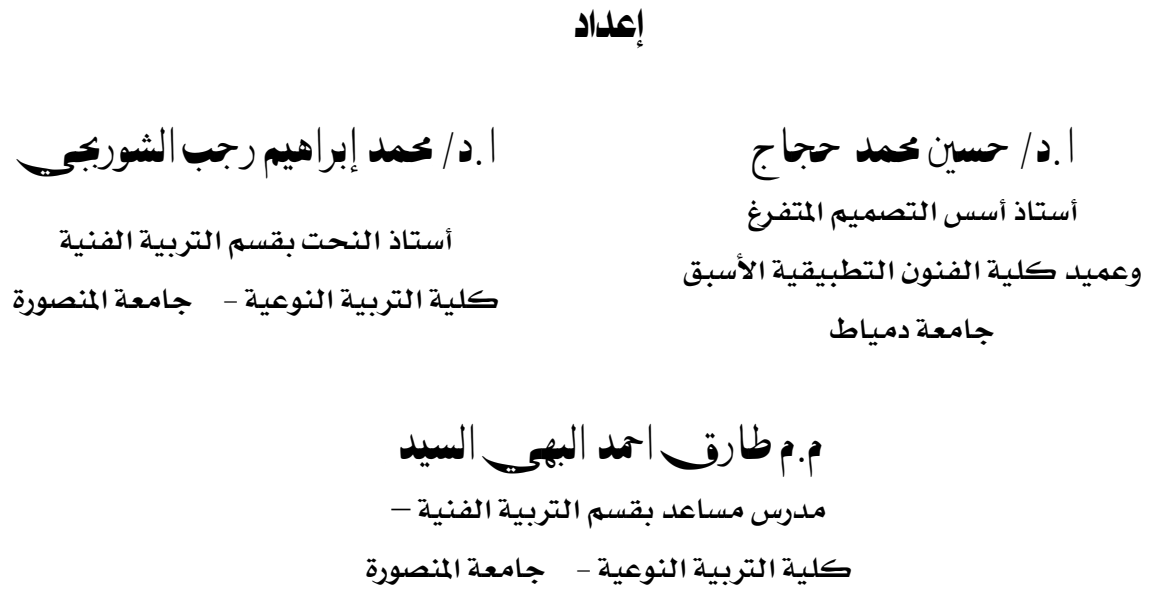




\title{
دور التصشيم ثلاثي الأبعاد في استمداث أعمال فنيه هماصره
}

\author{
إعداد

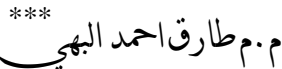

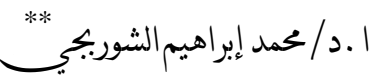

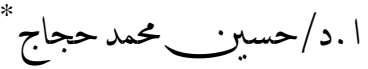 \\ هلخص البحث
}

إن مضمون التصميم هو انتقـاء للفكرة، للأسـلوب، للمـادة، لطريقـه التنفيـ، مـع الأخــ ـيِ

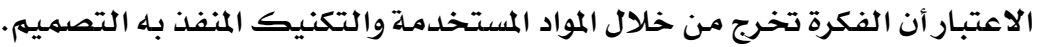

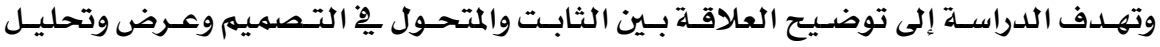

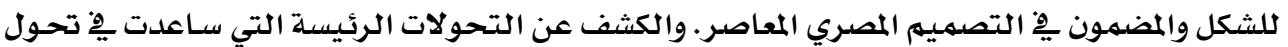
التصميم المصري المعاصر...

وتناولت الدراسة التحولات المعاصرة يِّ فن التصميهم يِّ الآونة الأخيرة عبر مسارها بـدرجات

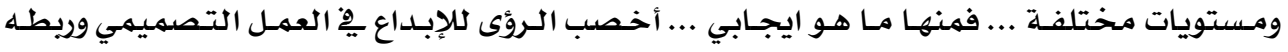

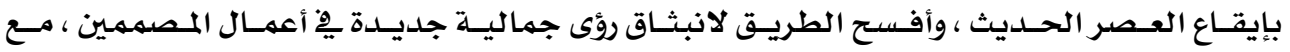

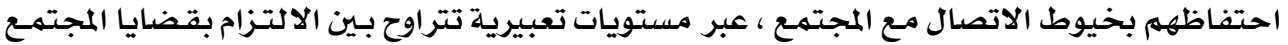

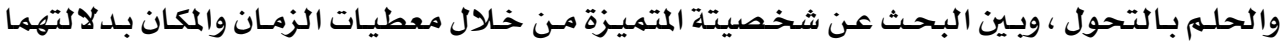

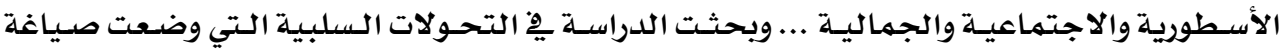

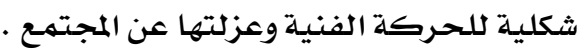

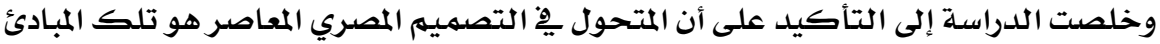

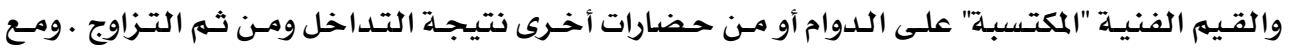

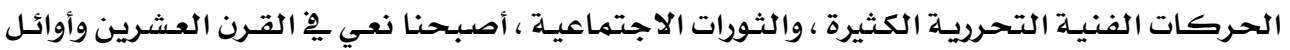

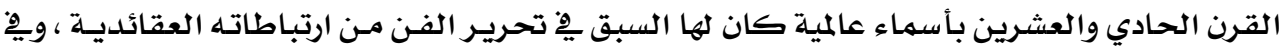

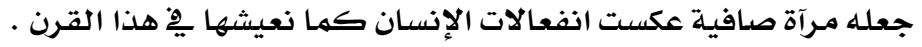

مقدمهن:

إن مضمون التصميم هو انتقاء للفكرة، للأسلوب، للمادة، لطريقه التنفيذ، مـع الأخذ ِيْ

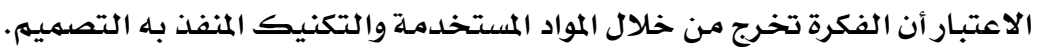
والفكرة لدي المصمهم تتكون لدي سعيه لابتكار ما يؤكد ذاته وتعبيره عن نفسـه كفرد يِ

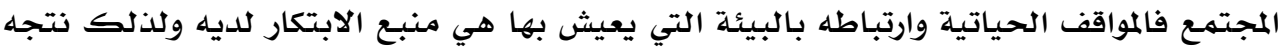

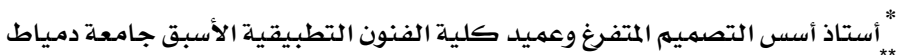

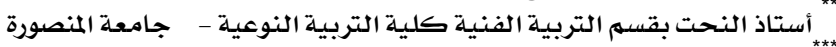

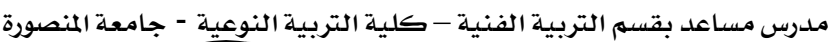




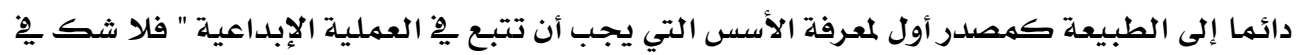

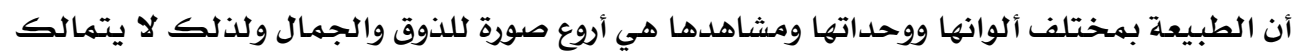

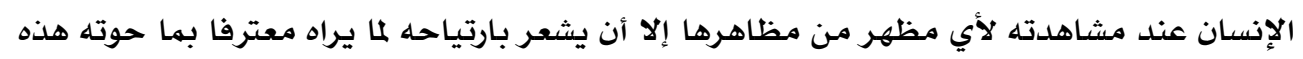

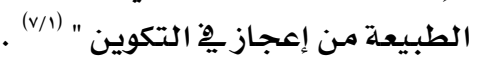

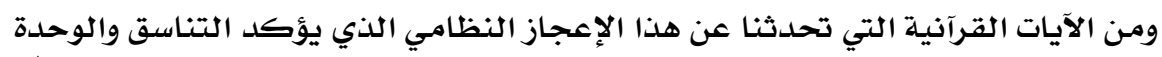

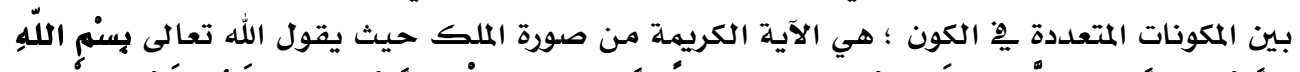

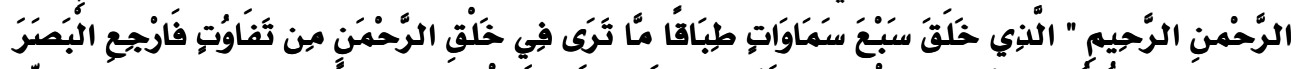

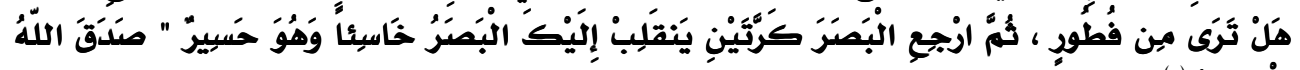

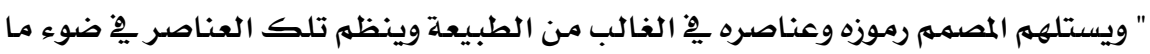

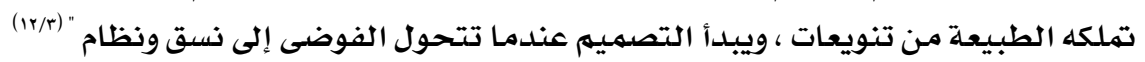

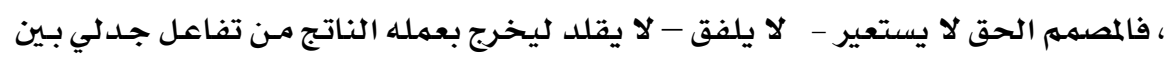

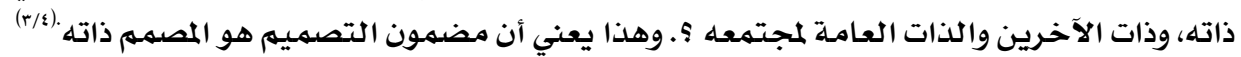

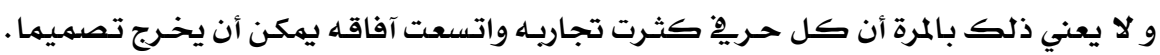

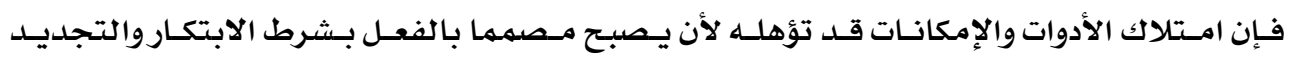

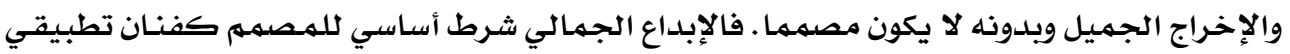

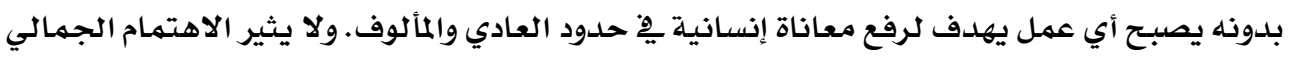
حيث إن الجدوى من ورائه هي الجانب النفعي المباشر.

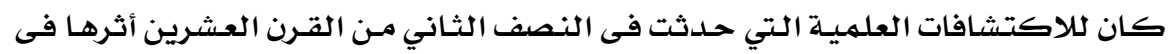

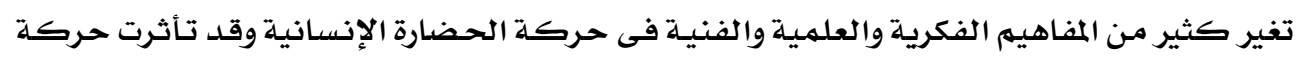

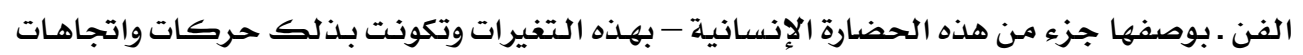

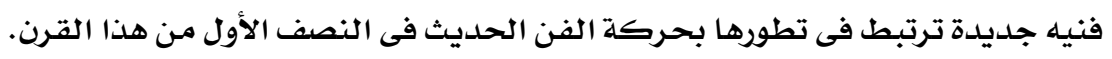

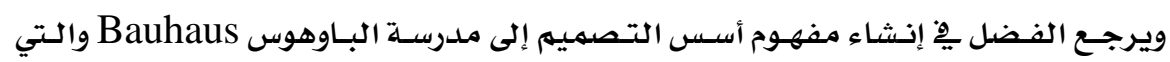

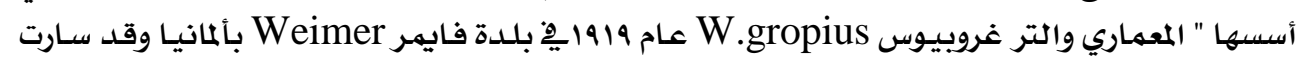

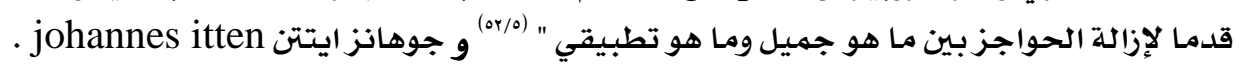

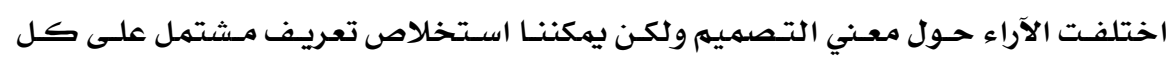

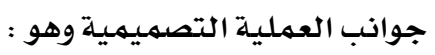

التصميمم هو تلك العملية الإبداعية التي تهدف إلىي وضـع حلـول لتلبيـة احتياجـات ملحسة

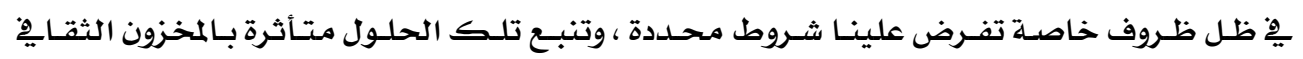

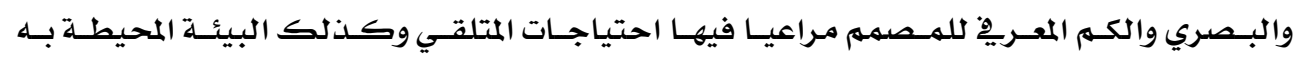
ثقافيا واجتماعيا 


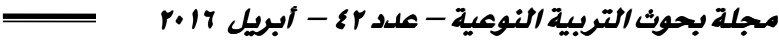

\section{وٌِِ ضوء العرض السابق يمكن تحديد مشكلة الدراسة ٍِِ التساؤلات التالية:}

ا. كيف توظف التقنيـات المعاصـرة على مختـارات مـن أعمـال الفـن لفنـانين مصريـين وأجانب .

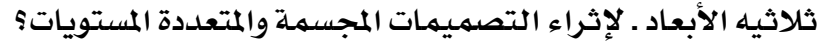

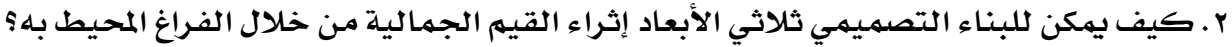

\section{أهمية الدوراسة:}

تتضح أهمية الدراسة الحالية يِّ النقاط التالية: .

ا. الكشف عن جماليات العلاقة بين التقنيات المعاصرة و التصميمات ثلاثيه الأبعاد.

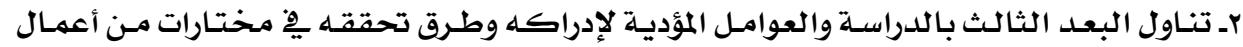
الفنانين المعاصرين.

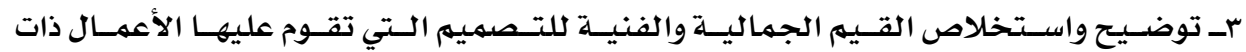
البعد الثالث.

هدف الدراسة:

تتحدد أهداف الدراسة الحالية فيما يلي: . • • توضيح العلاقة بين الثابت والمتحول يِ التصميه. • ـ عرض وتحليل للشكل والمضمون يِ التصميم المصري المعاصر.

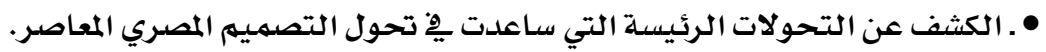

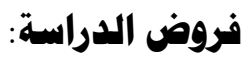

$$
\text { يقترح الباحث الفروض التالية: . }
$$

ا ـ توجد علاقة دالة بين التقنيات المعاصرة وإثراء القيم الجمالية.

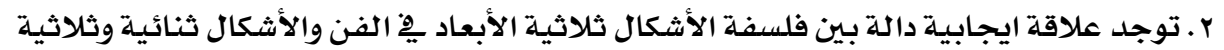

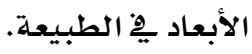

\section{هنهفج الدراسة:}

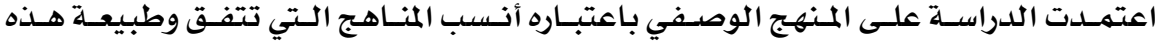

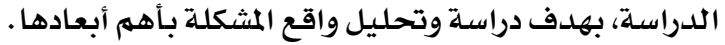

الإطار النظري للدراسة: مفهوم التصميم ثلاثي الابعاد ومقومات العمل الفني :

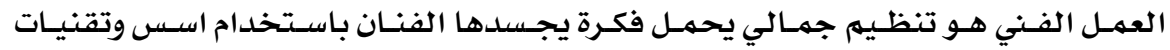

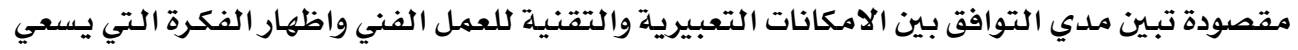

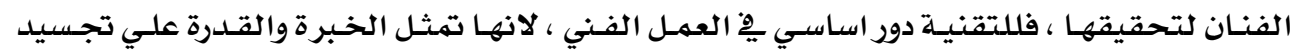

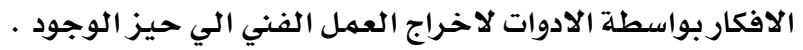




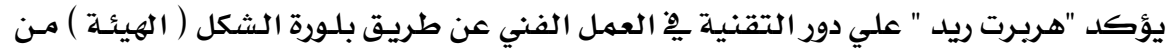

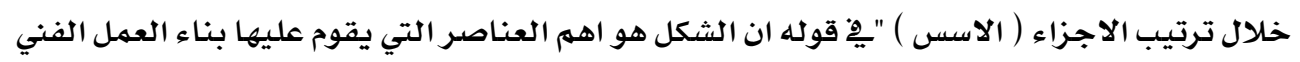

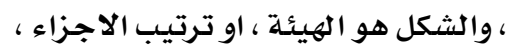

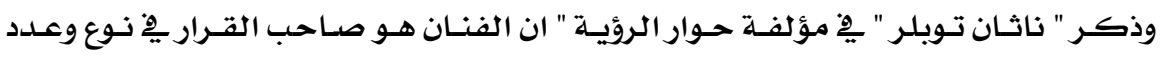

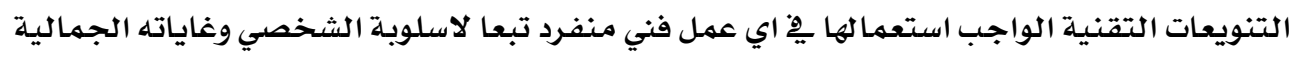

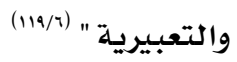

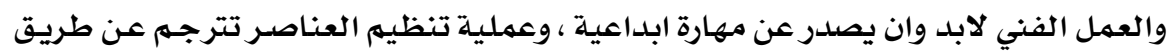

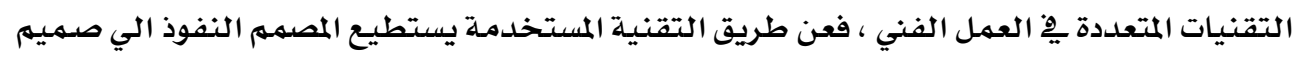

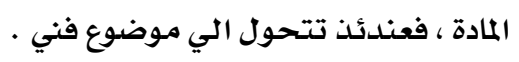

والتصميم يتكون من مفردات يختارها المصممم بما يراه محققا للهدف الذي يسعي لتاكيده

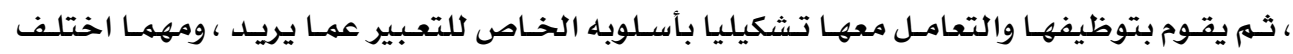

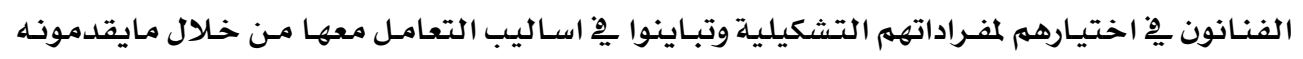

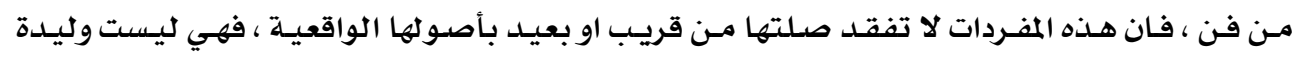

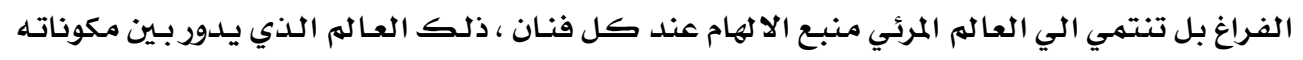

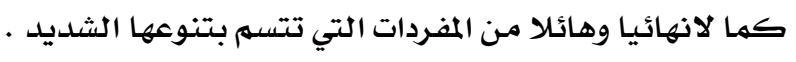

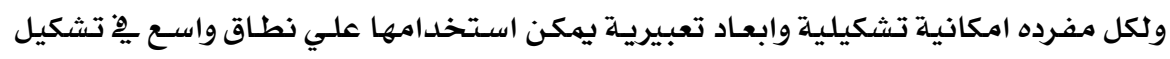

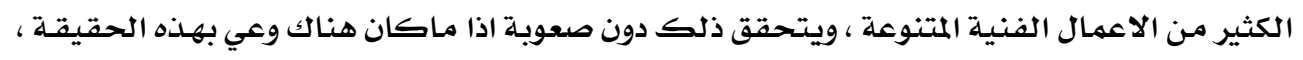

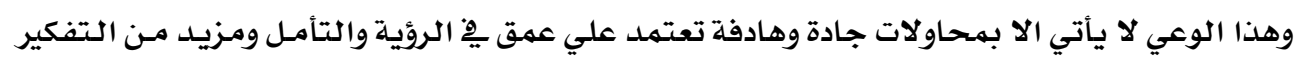

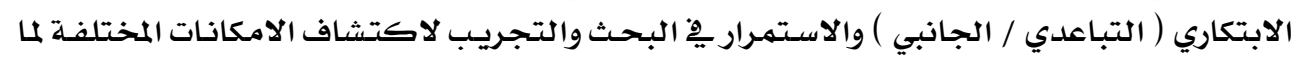

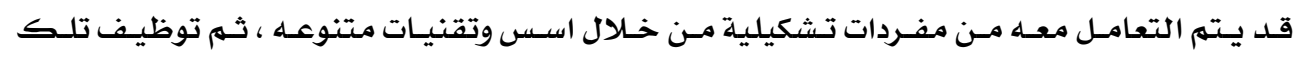

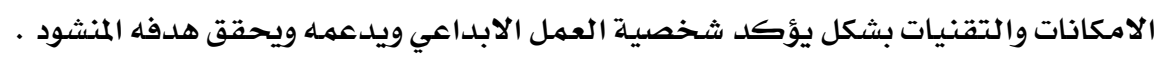

\section{العلاقة بين التقنيه والتصميم ثلاثي الابعاد:}

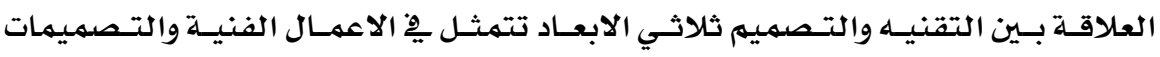

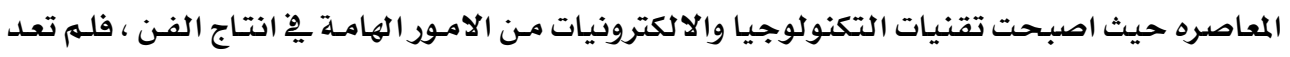

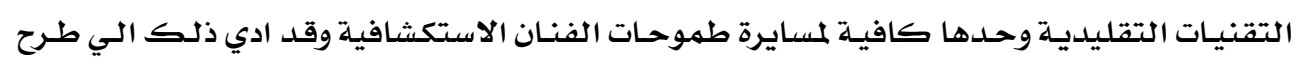

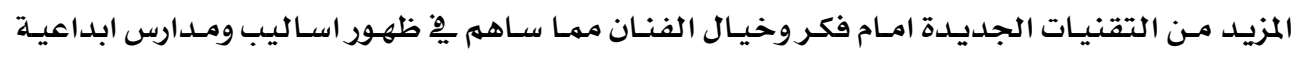

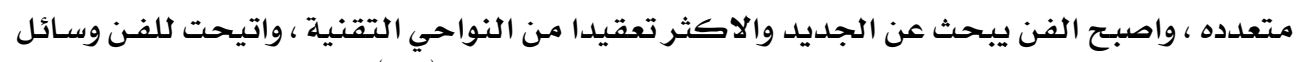

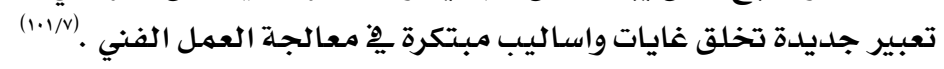

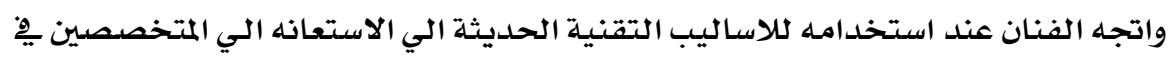

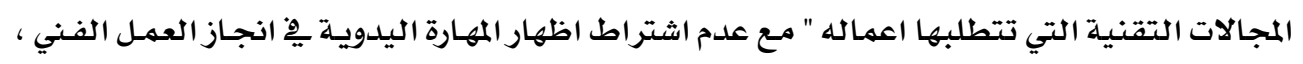

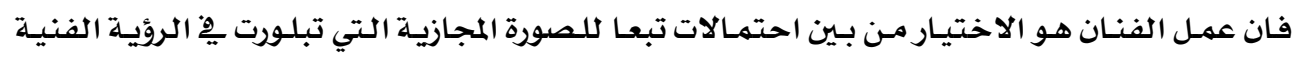


وتغير هدف الفن من مخاطبة العين الي مخاطبة العقل .

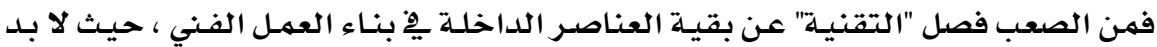
من توافر وحده تجمع هذه العناصر ، وتهثل التقنية النسيج الذي يربط تلك العناصر بعضها ببعض

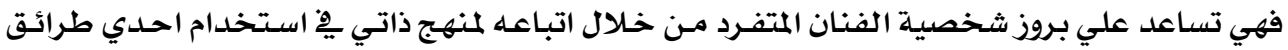

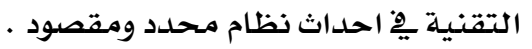

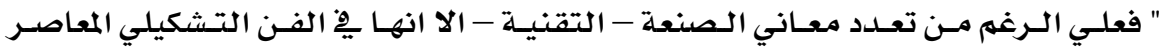

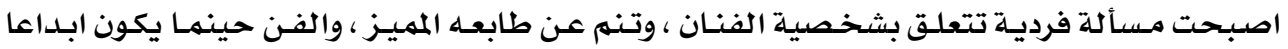

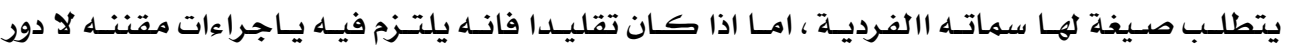

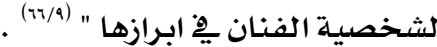

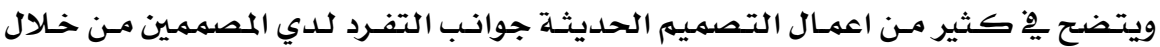

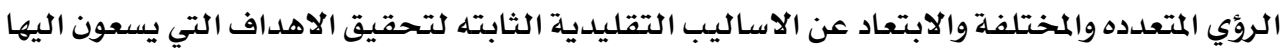

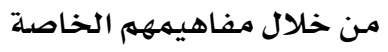

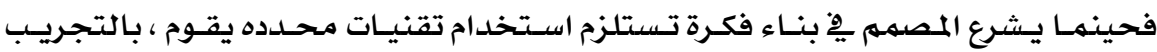

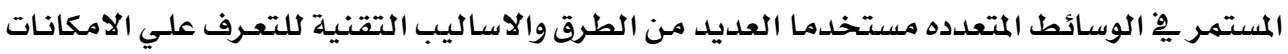
لتلك الوسائط المادية .

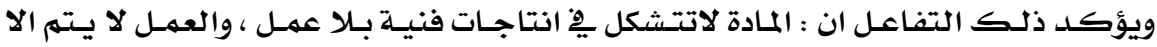

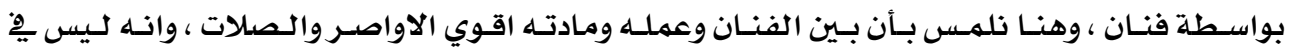

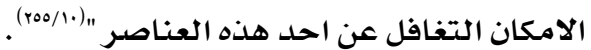

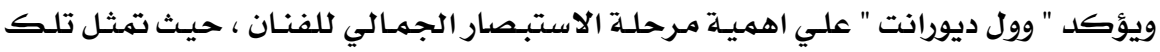

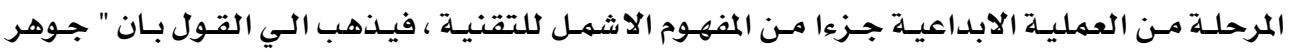

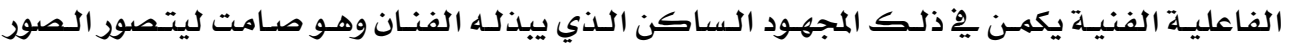

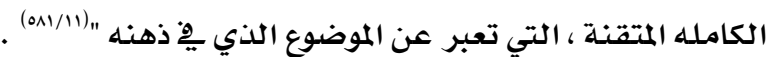

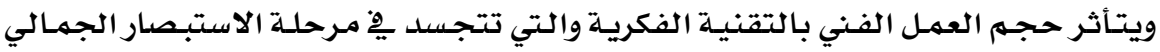

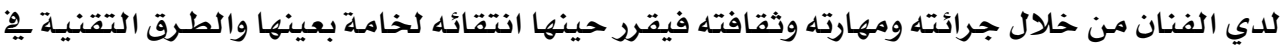

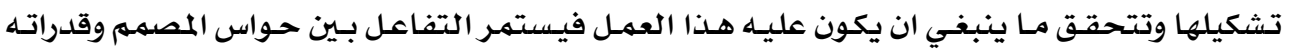

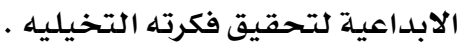

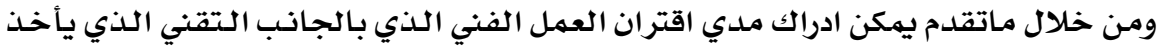

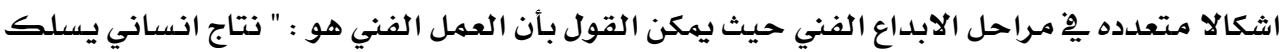

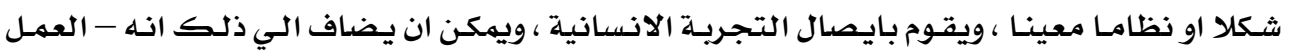

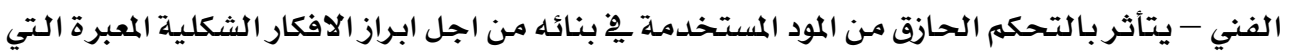

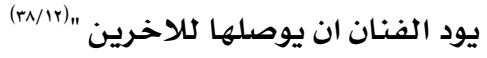




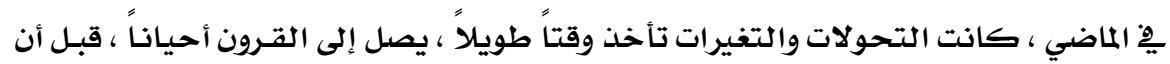

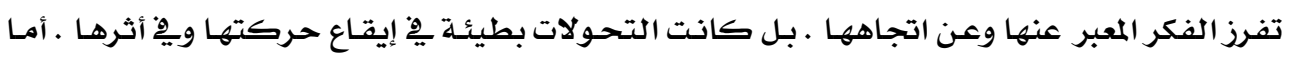

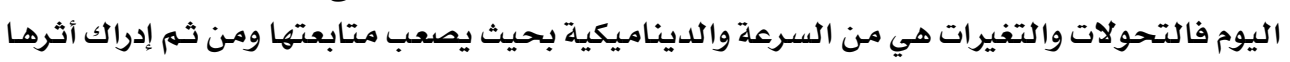
مِّ مختلف المجالات.

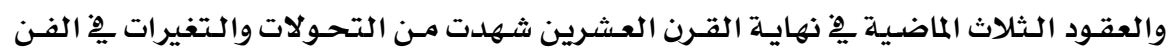

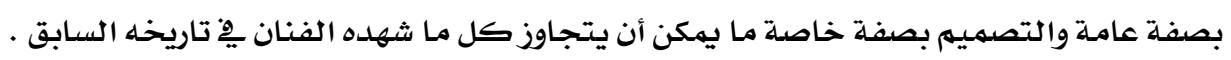

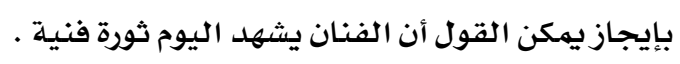

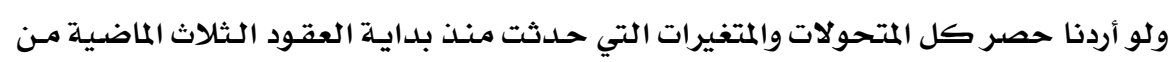

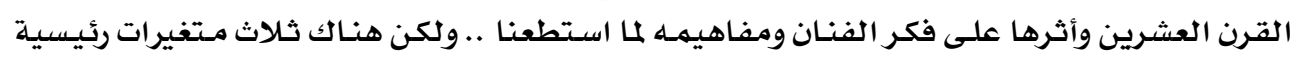

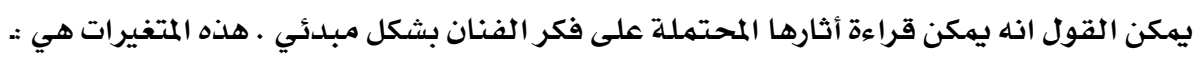

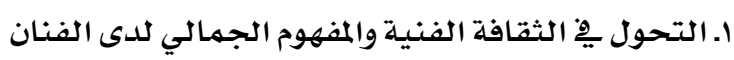

$$
\begin{aligned}
& \text { r. الثورة العلميلة الهائلة }
\end{aligned}
$$

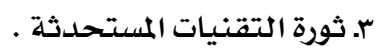

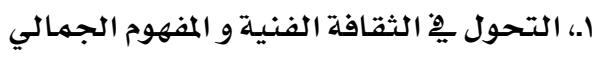

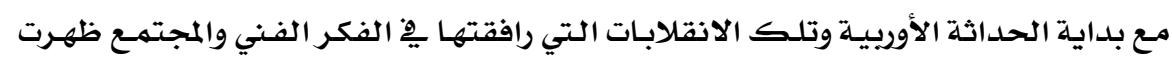

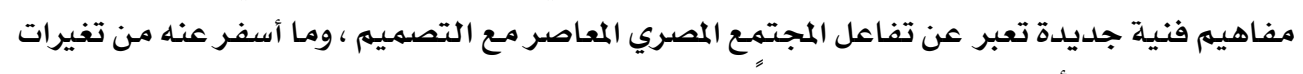

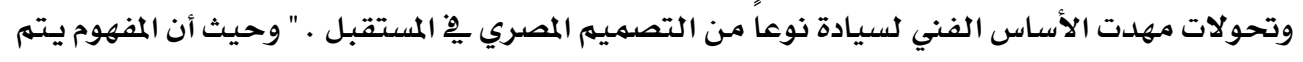

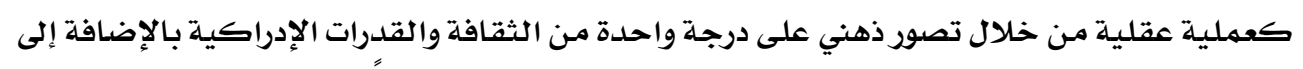

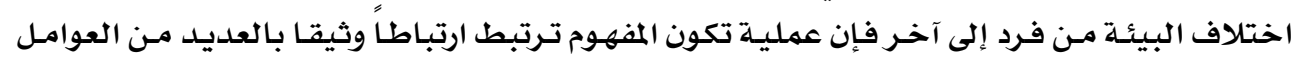

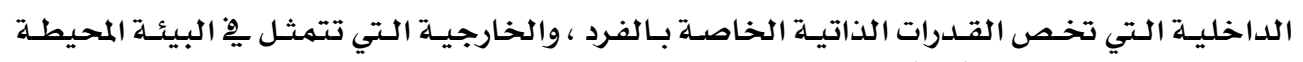

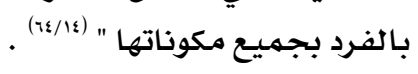

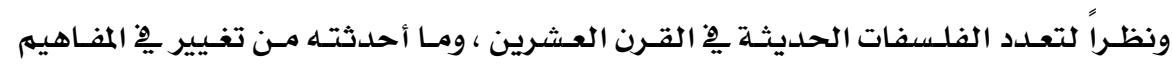

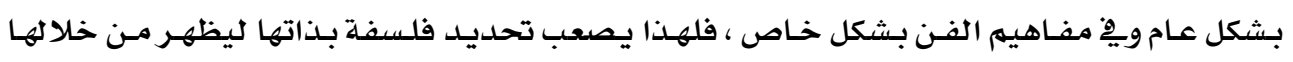

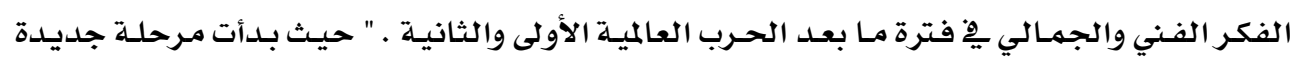

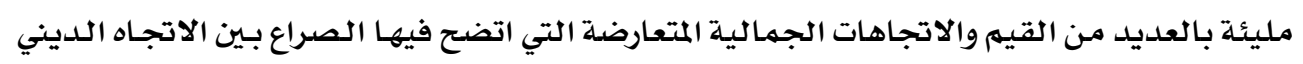

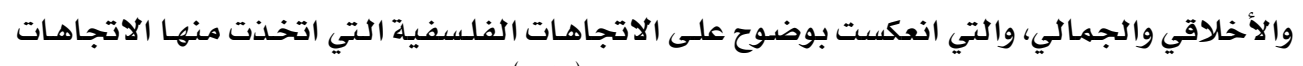
الفنية ، مفاهيم جديدة لتغيير واقع الفنان بِ المجتهمع " (198/10 ) .

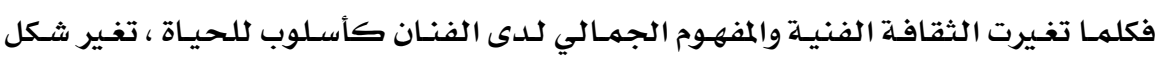

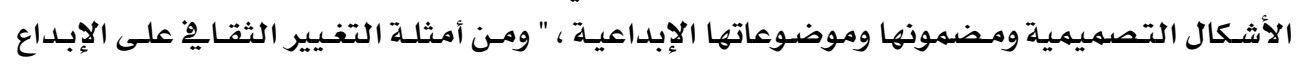

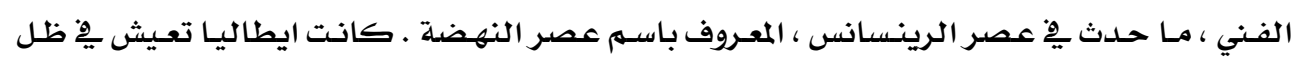




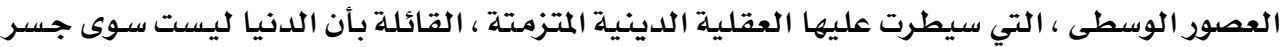

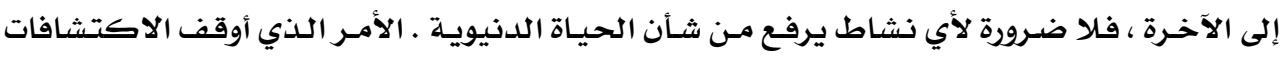

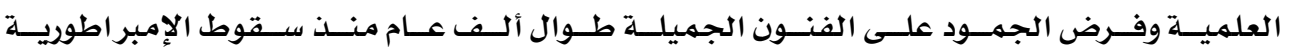

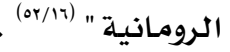

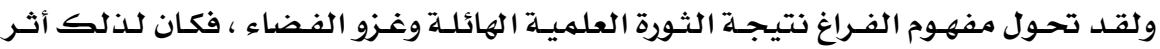

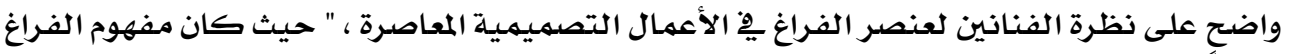

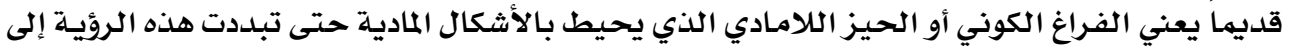

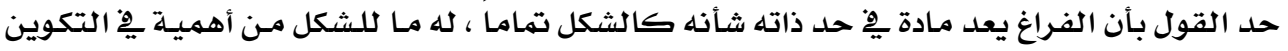

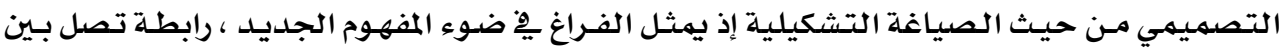

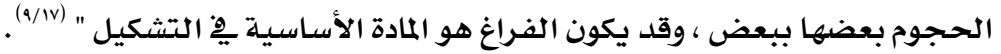

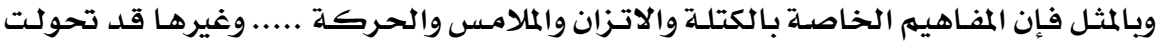

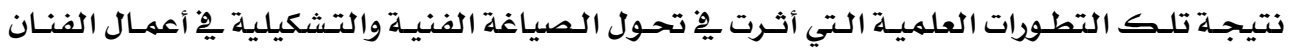

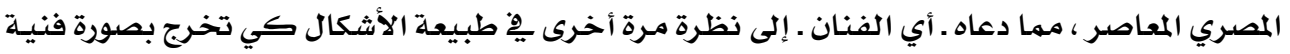

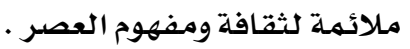

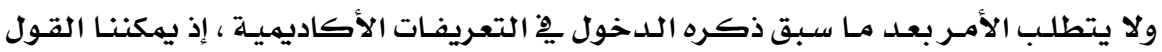

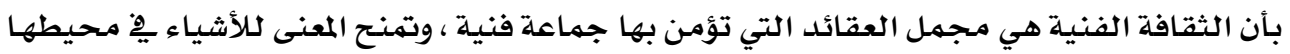

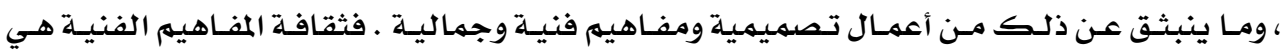

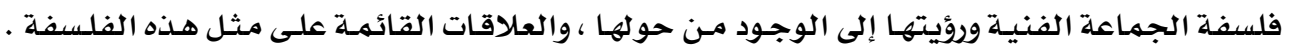

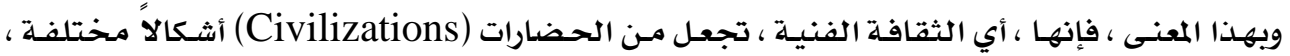

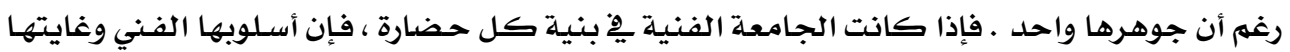
يتحددان وفقا للثقافة السائدة .

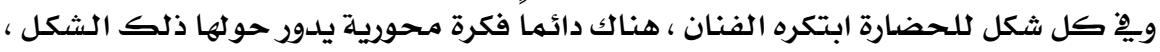

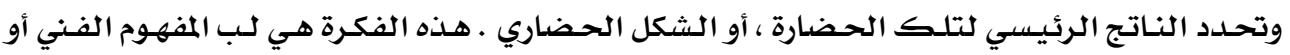

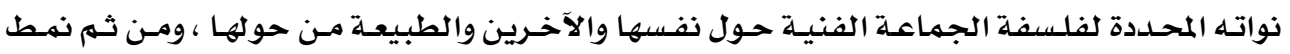

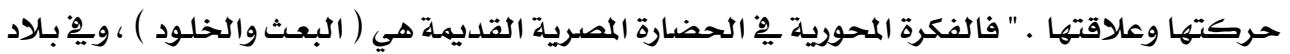

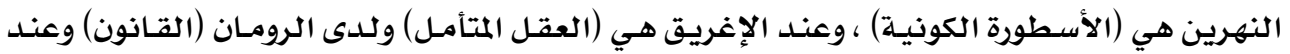

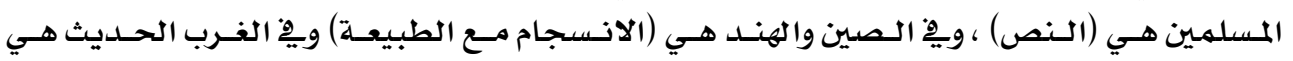

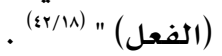

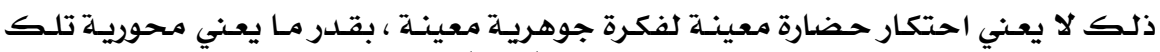

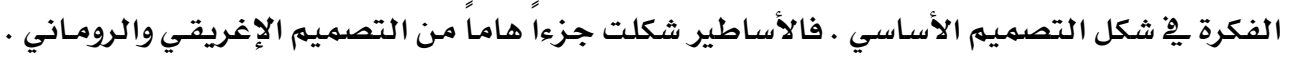

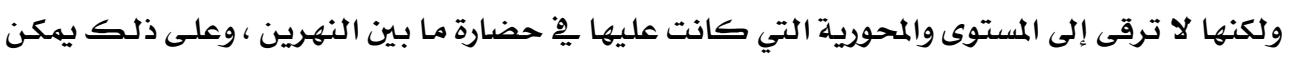




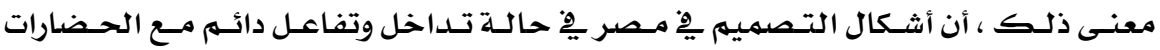

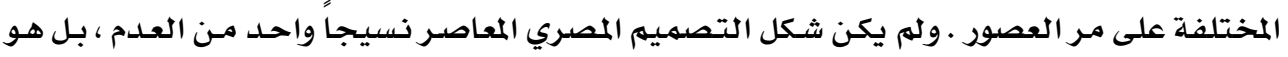

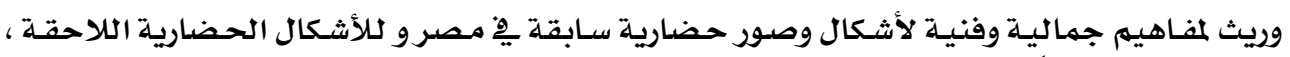

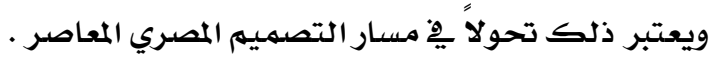

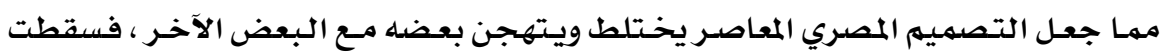

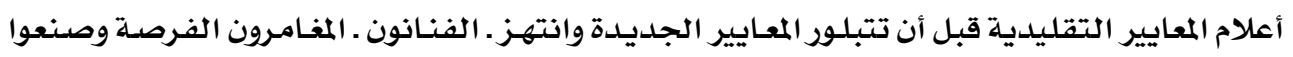

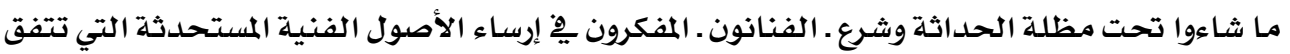

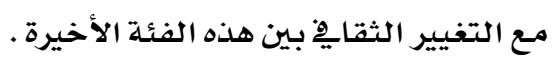

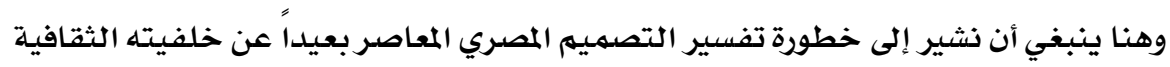

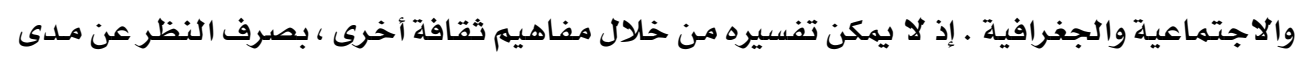

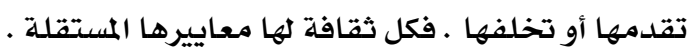

ونتيجة لهذا التحول يِ المفاهيم الفنية لدى الفنانين فقد اتجهوا إلى إيجاد صيـغ تشكيلية

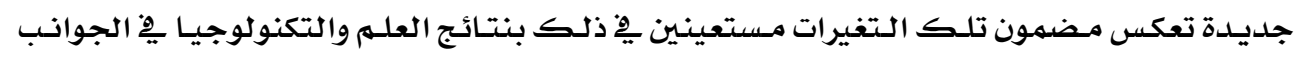

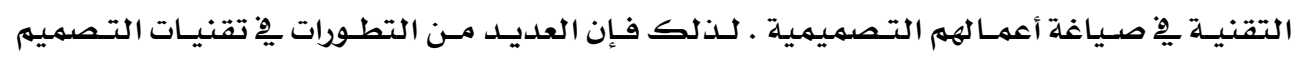

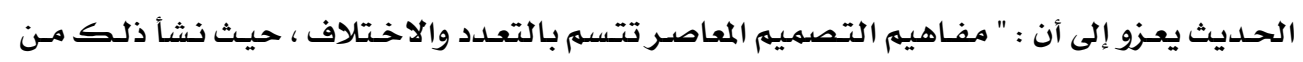

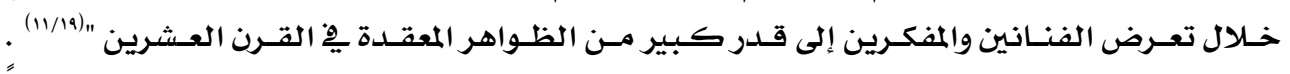

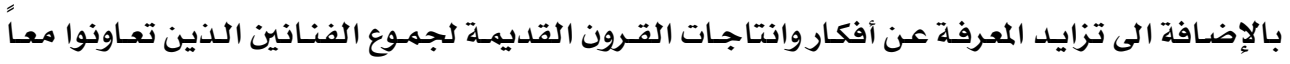

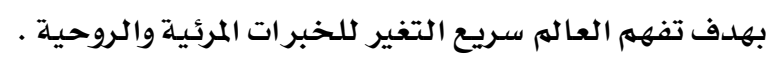

الثورة العلمية والتكنولوجية

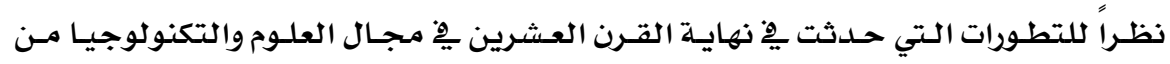

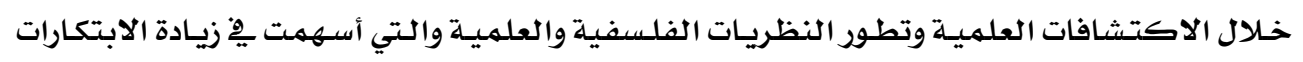

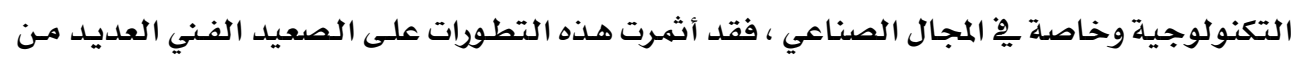

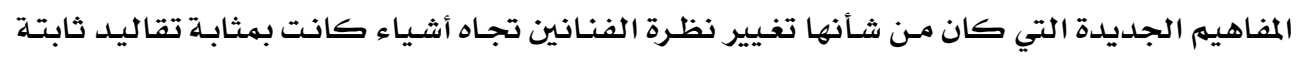

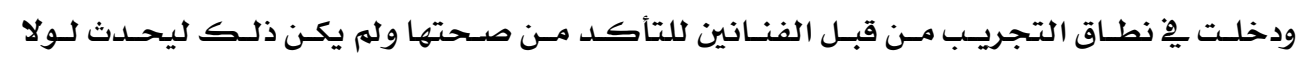

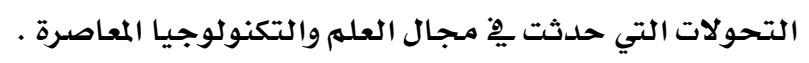

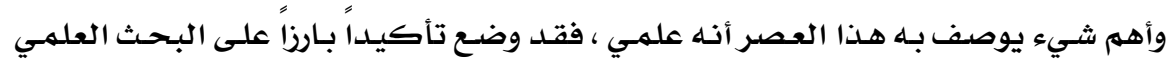

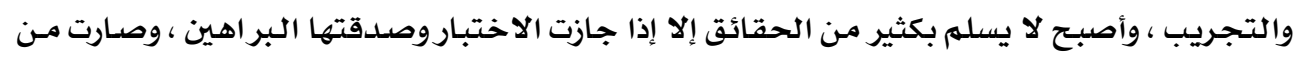

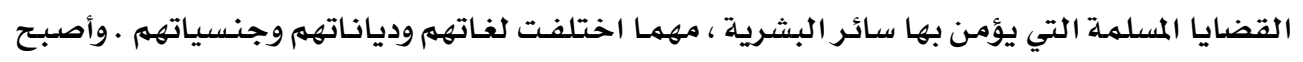

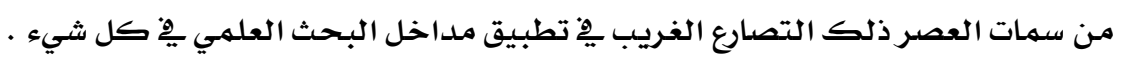

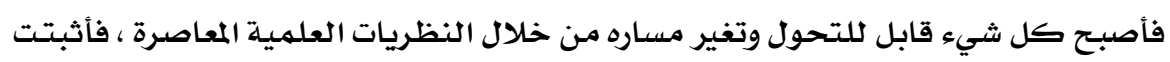

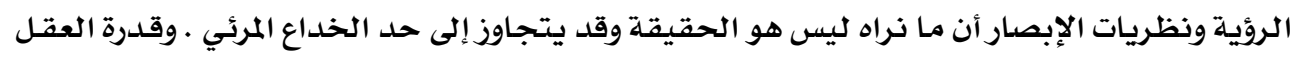

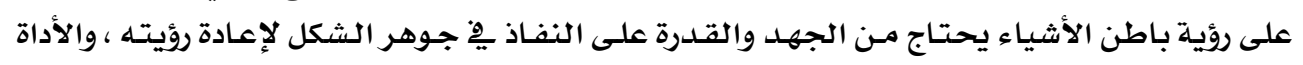




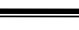

الجديدة ساعدت الفنان على هذه الرؤية يِّ النفاذ إلى جوهر الشيء وتجـاوز قشرة الشكل ، واستخراج الحقيقة الباطنة منـه .

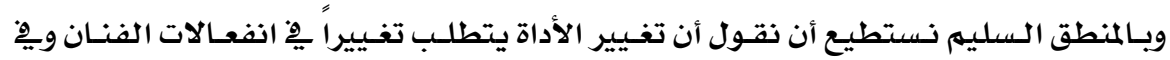

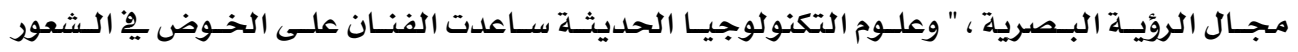

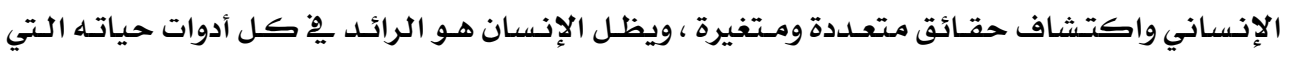

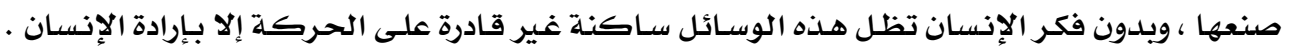

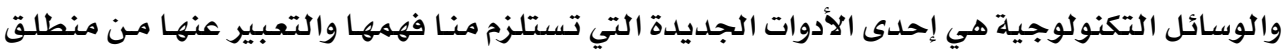

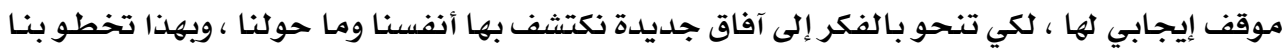

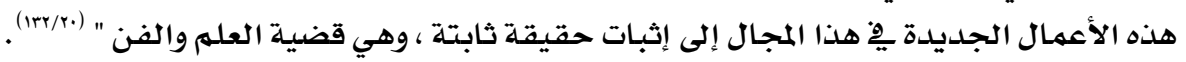

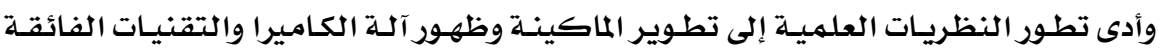

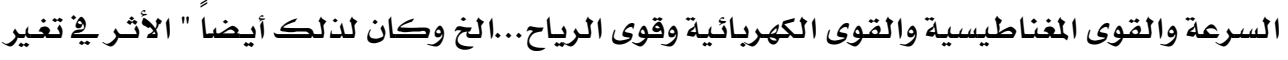

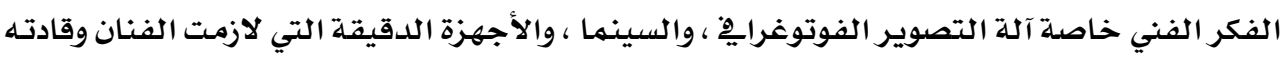
إلى التحرر من قيود الرؤية الواقعية " (1/ro/) .

فنتيجـة لارتبـاط التصميهم المصري المعاصـر بالاكتشافات العلميـة والتي أخـذت يِّن التطور

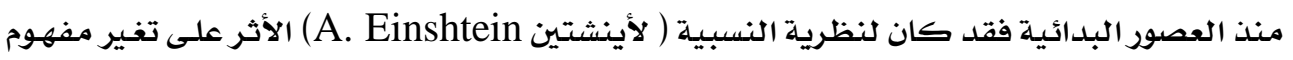

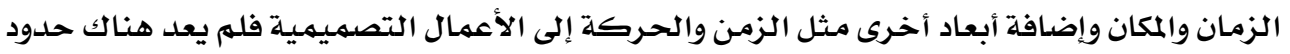

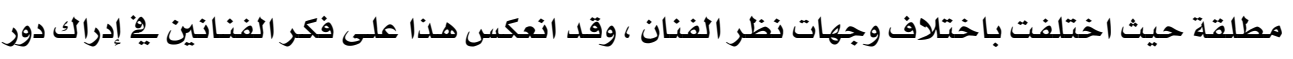

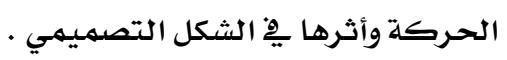

وتوالت الحركات الفنية يِّ صورة اتجاهات فكرية وتشكيلية كان لها الانعكاس المباشر على المئ

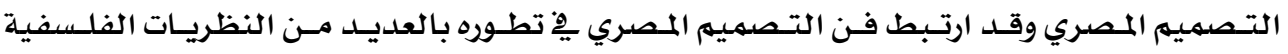

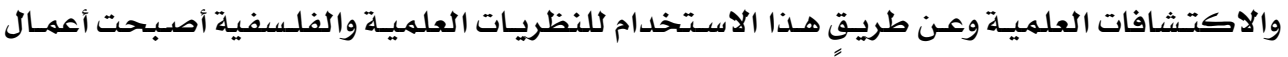

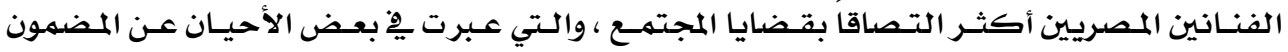

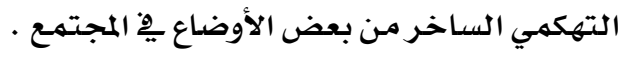

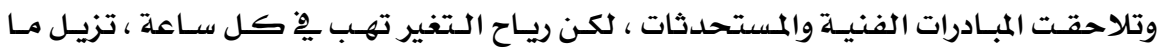

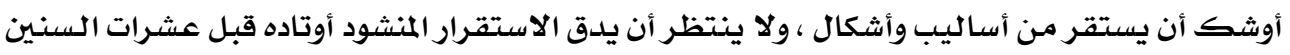

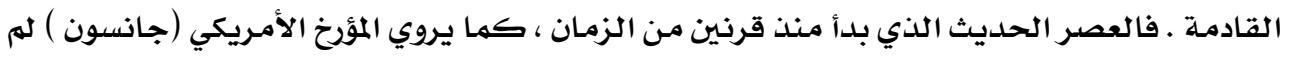

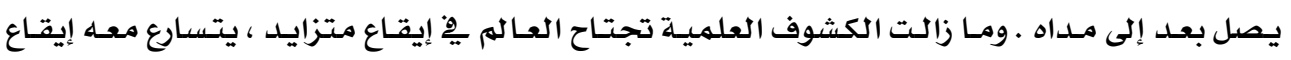

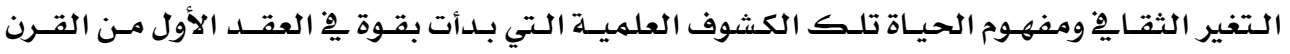

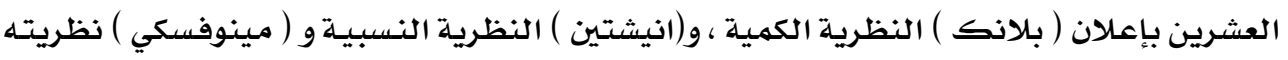

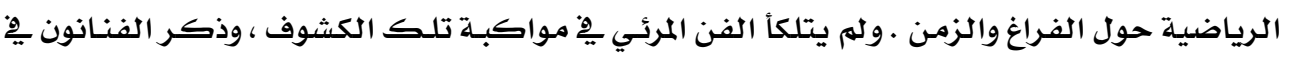

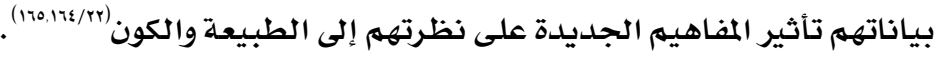




\section{التحول في التقنيات والخامات المستحدثة}

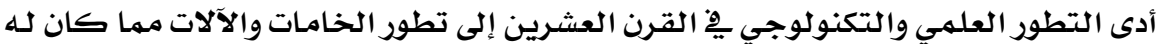

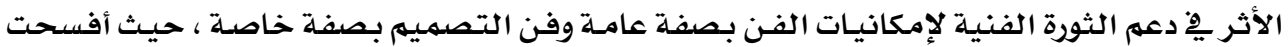

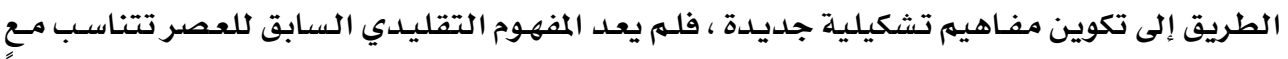

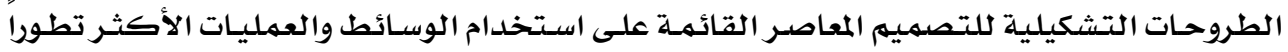

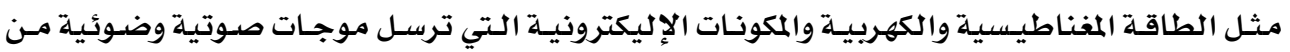

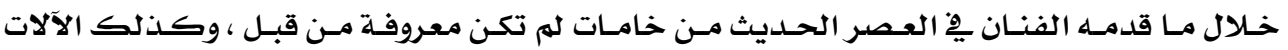

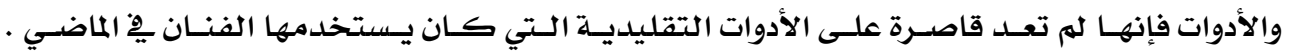

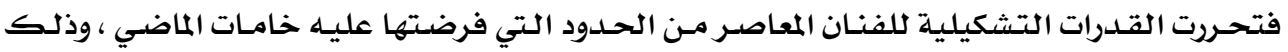

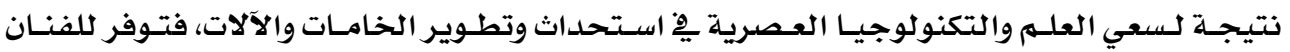

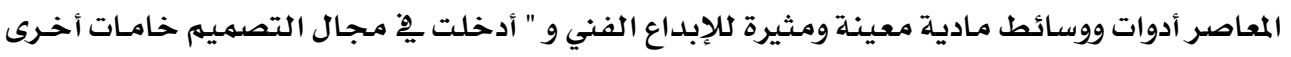

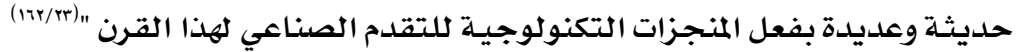

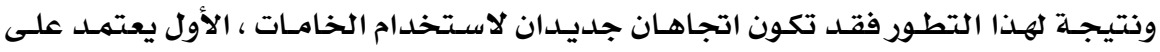

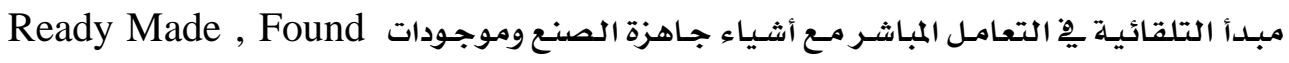

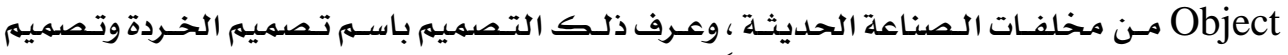

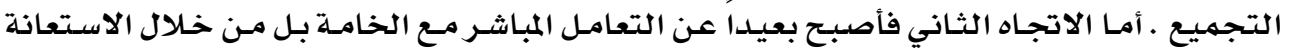

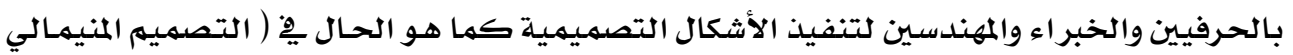
(rr/rs)( Minimal Design

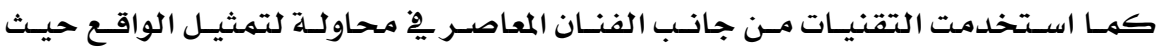

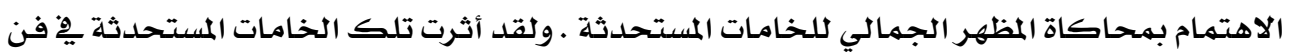

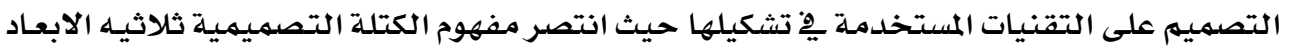

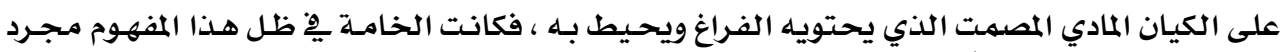

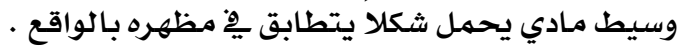

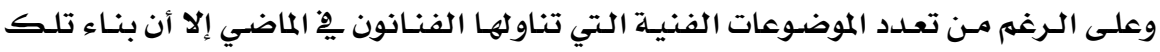

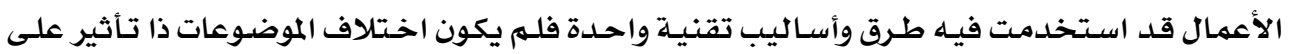

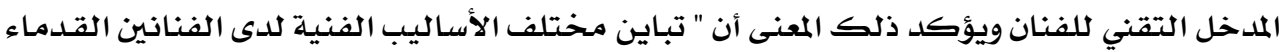

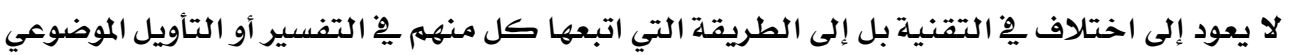

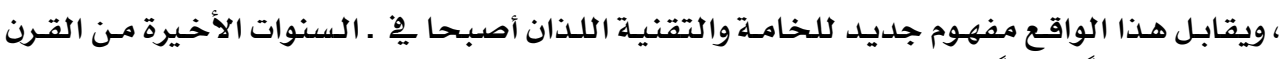

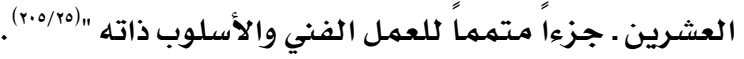
لذا ينبغي أن نؤكد على أن التقنيات الخاصدة بالفن ليست جوهر الشكل وإنما هي ظواهره

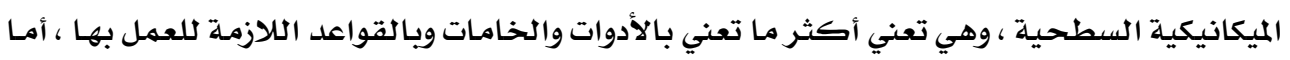

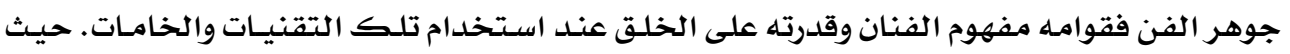




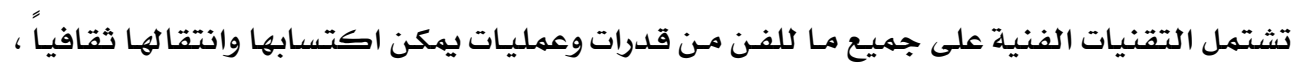

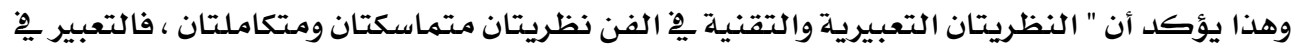

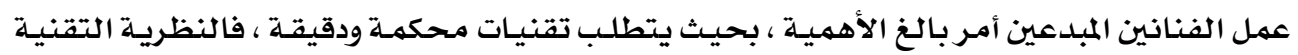

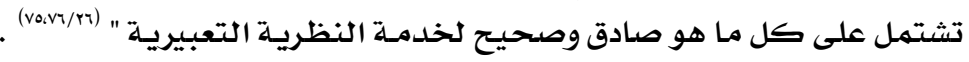

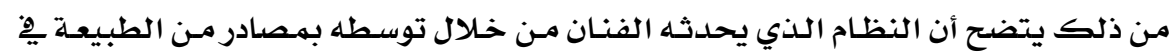

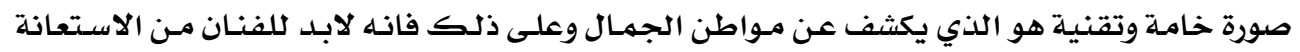

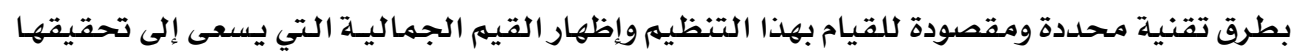

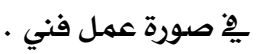

لذلك فقد تكونت يِّنهايـات القـرن العشرين مـن العصر الحـديث ، ظروف بيئيـة وجماليـة

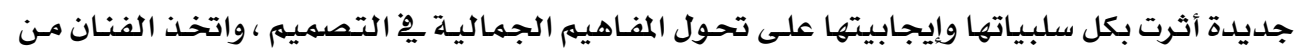

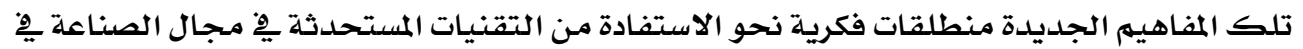

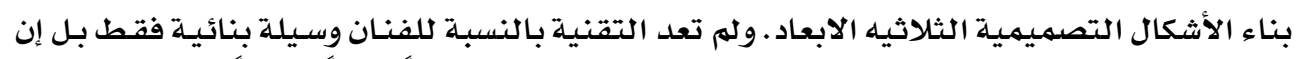

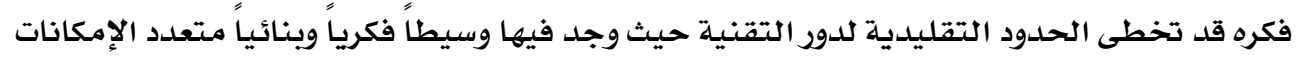

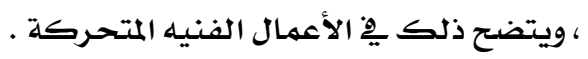

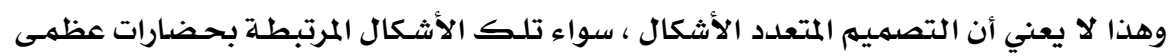

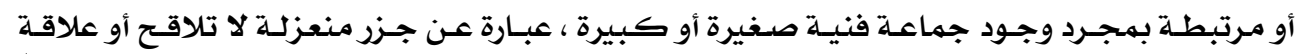

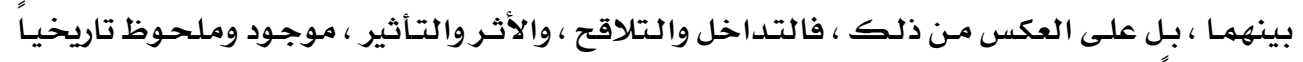

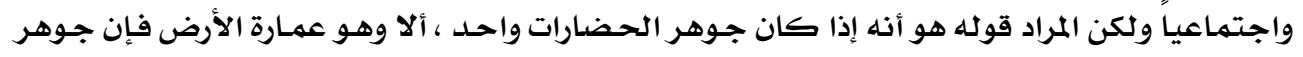

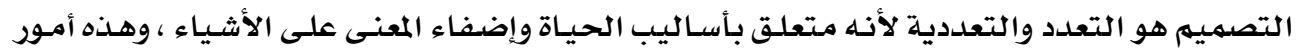

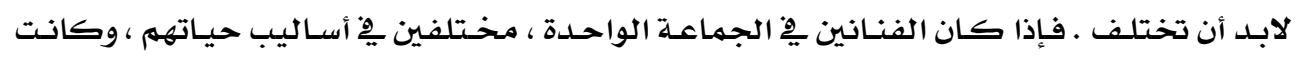

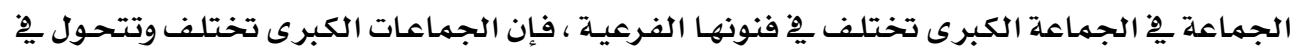

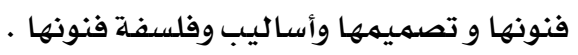

\section{نتائج الدراسة:}

للتحقـق مـن صـحة الفـرض الأول قـام البـاحـث بـدراســة العلاقــة بـين التقنيـات المعاصـرة و

$$
\text { التصميمات ثلاثيه الأبعاد. }
$$

\section{وتوصل الباحث إلى النتائج التالية:}

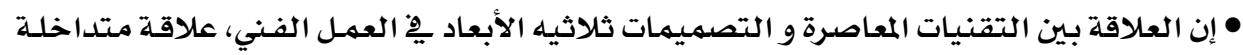

$$
\text { ومتشابكة لا يهكن الفصل بينها. }
$$

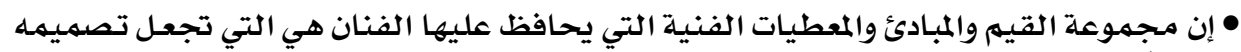

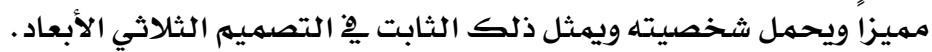

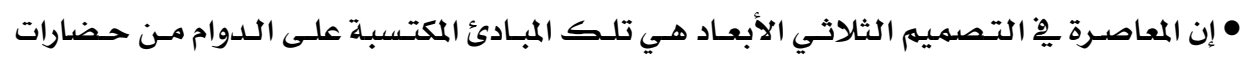
وثقافات أخرى نتيجة التداخل والتزاوج. 


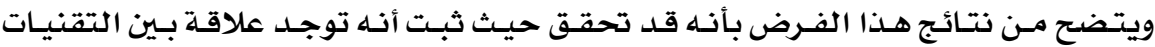

المعاصرة و التصميمات ثلاثيه الأبعاد.

وللتحقق من صححة الفرض الثاني قام الباحث بــراسـة العلاقـة بـين فلسفة الأثـكال ثلاثيـة

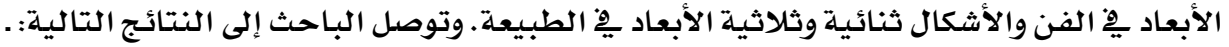

• إن الشكل والمضمون يِّ التصميم المصري المعاصر لا يفترقان، فلا وجـود لمضمون بـلا شكل وكل

شكل هو لمضمون معين

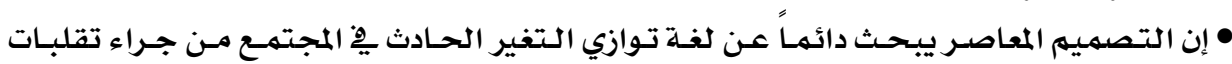

العصر وتطوراته.

• إن التصميهم المصري المعاصر يتجهـ إلى التأصيل ضمنه شروط التهن العصر.

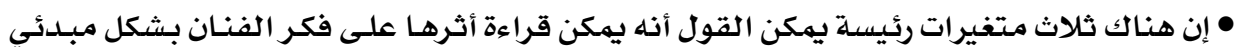

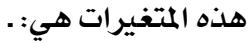

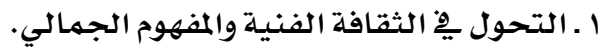

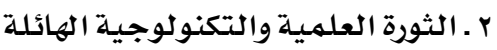

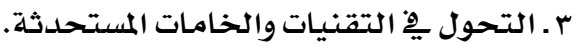

ويتضح من نتائج هـذا الفـرض بأنه قد تحقق حيث يوجـد ارتبـاط بـين الشكل والمضمون يو

التصميهم المصري المعاصر.

التوصيات الاقتزهة:

• ضرورة التأكيد على دور التصميم هِّ الحياة الجماهيرية وِِّ خدمة المجتمـع.

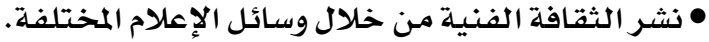

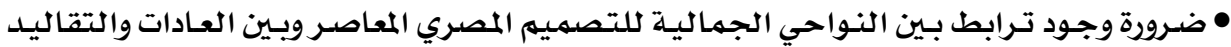

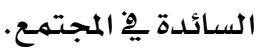

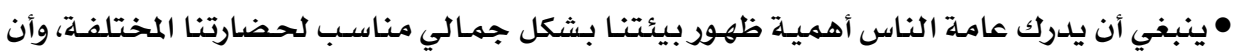

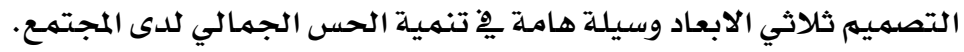

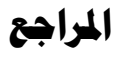

(1) حسين محمد يوسف ، حسن حمودة القادة : " فن ابتكار الأشكال الزخرفية ، تطبيقاتها العملية " مكتبـة ابن

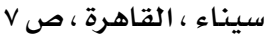

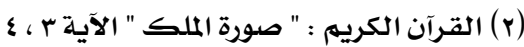

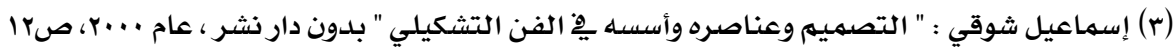

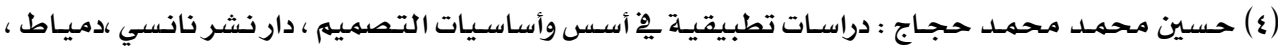

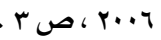

(๑) Johannes Itten, Design and Form, 1965, p. 52 


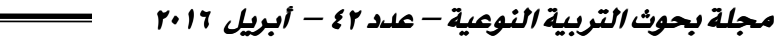

(ج) ناثان توبلر : حوار الؤيـة - مـدخل الي تـذوق الفن والتجريـة الجماليـة ، ترجمـة فخري خليل ، الهمعسسـة

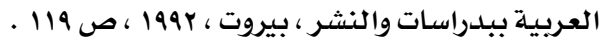

( $\vee$ James j kelly : the sculptural idea , burgess, New York, 1986 . p 101

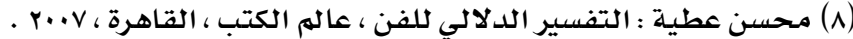

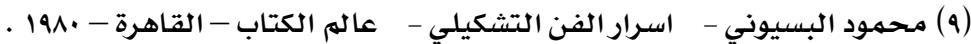

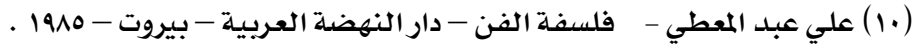

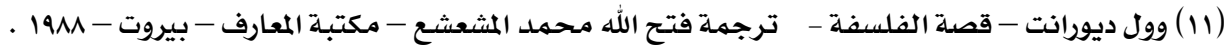

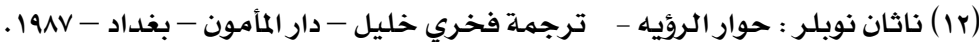

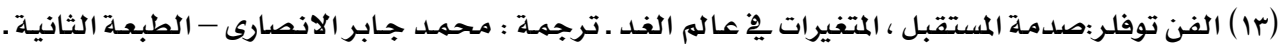

199. هضة مصر - القاهرة-

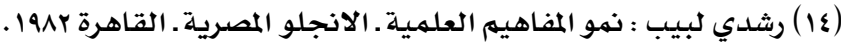

(10)Edward Lucie Smith: Movement in Art Since 1947: 1975 -Thame \&Hudson -

London - 1975.

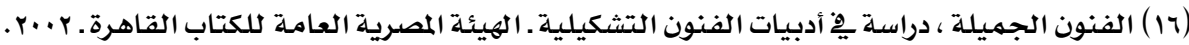

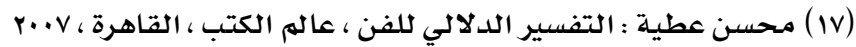

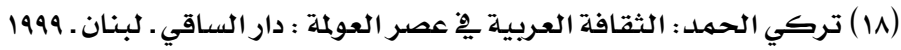

( 19 ) (21) Tony Richardson \&Nikosn Stangos: Concepts of Modern Art - Pen Gun books - London - 1985.

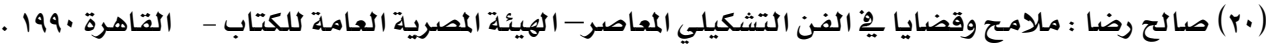

(Y) Allen Leapa: The Challenge of Modern Art - Great Britain -London -1997

(rr) مختار العطار : رواد الفن وطليعة التنوير ِِّ مصر ـ الجزء الثاني ـ الهيئة المصرية العامـة للكتاب ـ القـاهرة.

(Yr) Robert myron, Abner sundell : Modern Art in American - Cromwell Collier N.Y - 1971 .

(؟) فاروق وهبة : تغيير مفهوم الفن وفق مشكلات البيئسة - مجلـة فنون تشكيلية - المجلس الأعلى للثقافة -

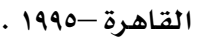

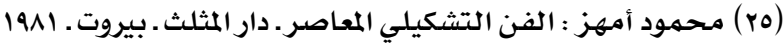

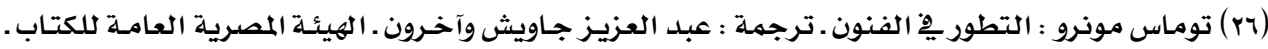

القاهرة . IQVY 


\section{The Role of Three - Dimensional Design in the Development}

\section{of Works of Contemporary Art}

\section{Study summary:}

The content of the design is to criticize the idea, the style, the material, the way of implementation, taking into account that the idea of graduated through the material and the technique used by the port design.

The study aims to clarify the relationship between fixed and variable in the design, presentation and analysis of the form and content in contemporary Egyptian design. And disclosure of the major transformations that have helped in the transformation of contemporary Egyptian design .

The study of contemporary transformations in the art of design in recent times across the track in varying and different levels ... some of which is positive ... the most fertile visions of creativity in design work and linked to the rhythm of modern times, and paved the way for the emergence of new insights aesthetic in the work of designers, while retaining thread Contact with the community, through the graphical levels ranging from commitment to community issues and dream shift, and the search for distinctive character through the data space and time style mythological, social and aesthetic ... The study examined the negative changes that put the drafting of formal artistic movement and isolation from the community.

The study concluded that the emphasis on the variable in the contemporary Egyptian design is that the principles and values art "acquired" always or of other civilizations as a result of overlap and then mating 